\title{
Mapping Highly Efficient Mixed-cation Pseudohalide-perovskite Solar Cells with a Scanning Transmission X-ray Microscope
}

Ming-Wei Lin ${ }^{1}$, Hung-Wei Shiu ${ }^{1}$, Kuo-Chin Wang ${ }^{2}$, Ming-Hsien Li $^{2}$, Yu-Ling Lai ${ }^{1}$, Takuji Ohigashi ${ }^{3}$, Nobuhiro Kosugi ${ }^{3}$, Tzung-Fang $\mathrm{Guo}^{2}$, Peter $\mathrm{Chen}^{2}$, and Yao-Jane Hsu ${ }^{1,2 *}$

${ }^{1}$ National Synchrotron Radiation Research Center, Hsinchu, Taiwan, R.O.C.

${ }^{2}$ Department of Photonics, National Cheng Kung University, Tainan, Taiwan, R.O.C.

${ }^{3}$ UVSOR Synchrotron, Institute for Molecular Science, Okazaki, Japan.

* Yao-Jane Hsu, yjhsu@ nsrrc.org.tw

The organic-inorganic hybrid perovskite structure has rapidly attracted much attention because of the highly efficient photovoltaic cells in which it serves as a light sensitizer [1]. The perovskites are typically metal-organic frameworks of form $\mathrm{ABX}_{3}$, in which $\mathrm{A}$ is $\mathrm{CH}_{3} \mathrm{NH}_{3}{ }^{+}(\mathrm{MA})$ or $\mathrm{CH}_{3}\left(\mathrm{NH}_{2}\right)_{2}{ }^{+}(\mathrm{FA})$ or $\mathrm{Cs}^{+}$, $\mathrm{B}$ is $\mathrm{Pb}^{2+}$ or $\mathrm{Sn}^{2+}$, and $\mathrm{X}$ is $\mathrm{I}^{-}$or $\mathrm{Cl}^{-}$or $\mathrm{Br}^{-}$. For example, methylammonium lead iodide $\left(\mathrm{MAPbI}_{3}\right)$ and its analogues exhibit novel properties such as ambipolar charge transport, a large absorption coefficient and an effective electron- or hole-diffusion length, making them suitable for photovoltaic applications. Among various perovskites, the mixed-cation lead pseudohalide perovskites were particularly successful with a large power-conversion efficiency (PCE) and satisfactory stability against moisture [2-3]. The large crystalline size with few trap states, increased entropy or decreased formation of solid solution are experimentally or theoretically proposed to interpret the origin of this high efficiency and stability. The variation of film morphologies is typically examined with a conventional TEM or SEM that provides only the bulk structure in a cross-sectional view or the surface topography in a top view. The necessity arises to improve the mapping capability to inspect the multilayer structures with a scaffold of an electrontransport layer (ETL)/perovskite/hole-transport layer (HTM) in perovskite-based solar cells. We have investigated the origin of the large PCE and the stability of mixed-cation pseudohalide perovskite solar cells using a scanning transmission X-ray microscope (STXM). In our experiments to fabricate perovskite solar cells, the mixed cation with formamidinium $\left(\mathrm{FA}: \mathrm{HC}(\mathrm{NH})_{2}\right)$ and $\mathrm{Cs}$ cations replaced methylammonium. To improve the PCE efficiency and structural stability, we used lead thiocyanate $\left(\mathrm{Pb}(\mathrm{SCN})_{2}\right)$ as dopant so that the thiocyanate $\left(\mathrm{SCN}^{-}\right)$anions replaced the halide ions in the tetragonal sites of the unit lattice of perovskite $\mathrm{FA}_{0.9} \mathrm{Cs}_{0.1} \mathrm{PbI}_{3}$ solar cells. The cell devices with mesoscopic titania as scaffold/electron-transport layer and spiro-OMeTAD as hole-transport layer were examined for the photovoltaic performance under standard illumination conditions. PCE greater than $16 \%$ was achieved with optimized $\mathrm{Pb}(\mathrm{SCN})_{2}$ doping relative to $13.9 \%$ for cells without $\mathrm{Pb}(\mathrm{SCN})_{2}$. To understand the origin of this improved efficiency and structural stability, we used a STXM to examine the chemical structure and morphology. The samples of $\mathrm{FA}_{0 .} \mathrm{Cs}_{0.1} \mathrm{PbI}_{3}$ cuboids and with varied $\mathrm{Pb}(\mathrm{SCN})_{2}$ concentration in molar ratios $5 \%$, and $10 \%$ were prepared in our laboratory. The NEXAFS absorption spectra and STXM images at varied absorption edges, such as the C, O, N K-edge and Ti L-edge, were recorded at BL 09A2 spectroscopy of Taiwan Light Source at NSRRC and at BL4U in UVSOR Synchrotron in Japan, respectively.

To study the effect of doping of $\mathrm{Pb}(\mathrm{SCN})_{2}$ on the efficiency and stability, we prepared pristine perovskite $\mathrm{FA}_{0.9} \mathrm{Cs}_{0.1} \mathrm{PbI}_{3}$ and $\mathrm{Pb}(\mathrm{SCN})_{2}$-doped $\mathrm{FA}_{0.9} \mathrm{Cs}_{0.1} \mathrm{PbI}_{3}$ and spin cast them on mesoporous $\mathrm{TiO}_{2}$ layers (mp$\mathrm{TiO}_{2}$ ) that were pre-cast on $\mathrm{SiN}$ membranes. Figure 1 displays STXM images of the $\mathrm{C} K$-edge acquired at $287.6 \mathrm{eV}$, which is attributed to a $\mathrm{C}-\mathrm{N} \sigma^{*}$ resonance of $\mathrm{FA}\left(\mathrm{HC}^{*}(\mathrm{NH})_{2}\right)$ in $\mathrm{FA}_{0 .} \mathrm{Cs}_{0.1} \mathrm{PbI}_{3}$ with $\mathrm{Pb}(\mathrm{SCN})_{2}$ doped at $5 \%$ (Fig. a) and $10 \%$ (Fig. b). Compared to pristine $\mathrm{FA}_{0 .} \mathrm{Cs}_{0.1} \mathrm{PbI}_{3}$ (that shows no contrast), the 
$5 \%$-doped $\mathrm{FA}_{0.9} \mathrm{Cs}_{0.1} \mathrm{PbI}_{3}$ shows bright cuboids and a few black rods. In contrast, $10 \%$ doped $\mathrm{FA}_{0.9} \mathrm{Cs}_{0.1} \mathrm{PbI}_{3}$ expresses similar bright cuboids but more black sticks and irregular blocks that show black

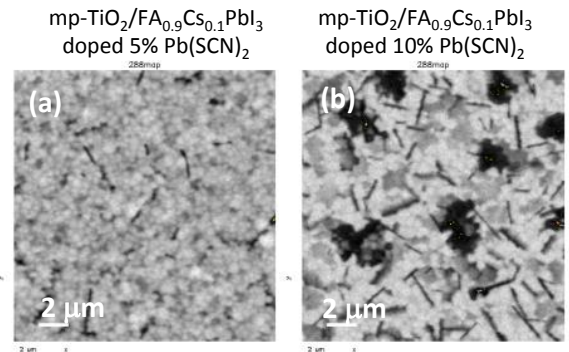

$5 \% \mathrm{~Pb}(\mathrm{SCN})_{2}$ doped- $\mathrm{FA}_{0.9} \mathrm{Cs}_{0.1} \mathrm{Pbl}_{3}$

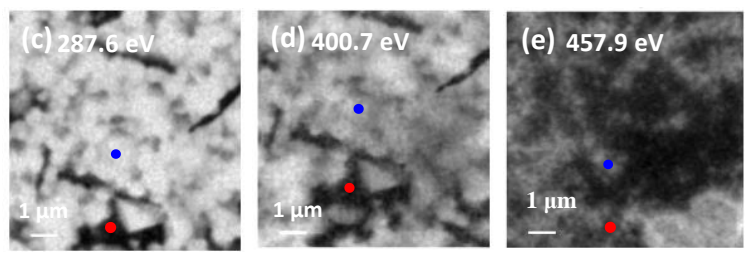

Figure 1. STXM OD images of $\mathrm{C} K$-edge at $287.6 \mathrm{eV}$ for (a) $\mathrm{SiN} / \mathrm{mp}-\mathrm{TiO}_{2} / 5 \% \mathrm{~Pb}(\mathrm{SCN})_{2}$ doped-FA ${ }_{0.9} \mathrm{Cs}_{0.1} \mathrm{PbI}_{3}$, and (b) $\mathrm{SiN} / \mathrm{mp}-$ $\mathrm{TiO}_{2} / 10 \% \mathrm{~Pb}(\mathrm{SCN})_{2}$ doped-FA ${ }_{0.9} \mathrm{Cs}_{0.1} \mathrm{PbI}_{3}$. The OD images of (c) $\mathrm{C} K$-edge at $287.6 \mathrm{eV}$, (d) $\mathrm{N}$ $K$-edge at $400.7 \mathrm{eV}$ and (e) Ti $L$-edge at 457.9 $\mathrm{eV}$ for $5 \% \mathrm{~Pb}(\mathrm{SCN})_{2}$ doped-FA $0.9 \mathrm{Cs}_{0.1} \mathrm{PbI}_{3}$. All images have subtracted the pre-edge image. and grey contrast, which apparently result from too much $\mathrm{Pb}(\mathrm{SCN})_{2}$ dopant. A comparison of chemical mapping of the $\mathrm{C} K$-edge at $287.6 \mathrm{eV}, \mathrm{N} K$-edge at $400.7 \mathrm{eV}$ and $\mathrm{Ti} L$-edge at $457.9 \mathrm{eV}$ for $5 \%$ $\mathrm{Pb}(\mathrm{SCN})_{2}$ is shown in Figure 1(c), (d) and (e), respectively. Both $\mathrm{C}$ and $\mathrm{N}$ mapping, which were acquired at characteristic absorption features of $\mathrm{FA}_{0.9} \mathrm{Cs}_{0.1} \mathrm{PbI}_{3}$ perovskite, display the same features and contrast that are not directly correlated with the distribution of $\mathrm{mp}-\mathrm{TiO}_{2}$. The crystalline size of $\mathrm{Pb}(\mathrm{SCN})_{2}$ doped-FA ${ }_{0.9} \mathrm{Cs}_{0.1} \mathrm{PbI}_{3}$ perovskite are, however, significantly decreased when grown on $\mathrm{mp}$ $\mathrm{TiO}_{2}$. This condition indicates that $\mathrm{Pb}(\mathrm{SCN})_{2}$ and mesoporous $\mathrm{TiO}_{2}$ play key important roles to affect the growth of perovskite crystallites. The optimized addition of $\mathrm{Pb}(\mathrm{SCN})_{2}$ is advantageous to enlarge the crystal size of $\mathrm{FA}_{0.9} \mathrm{Cs}_{0.1} \mathrm{PbI}_{3}$ on $\mathrm{mp}-\mathrm{TiO}_{2}$. To comprehend thoroughly the distribution of heterostructure layers, we display in Figure 2 the chemical maps of the $\mathrm{N} K$-edge and Ti $L$-edge of $\mathrm{SiN} / \mathrm{mp}-\mathrm{TiO}_{2} / 5 \% \mathrm{~Pb}(\mathrm{SCN})_{2}$ doped-FA ${ }_{0 .} \mathrm{Cs}_{0.1} \mathrm{PbI}_{3}$, and $\quad \mathrm{SiN} / \mathrm{mp}-\mathrm{TiO}_{2} / 10 \% \quad \mathrm{~Pb}(\mathrm{SCN})_{2} \quad$ doped$\mathrm{FA}_{0.9} \mathrm{Cs}_{0.1} \mathrm{PbI}_{3}$, which are maps of optical density (OD) obtained at the characteristic absorption features of $\mathrm{FA}_{0 .} \mathrm{Cs}_{0.1} \mathrm{PbI}_{3}$ and $\mathrm{mp}-\mathrm{TiO}_{2}$. There are notable additional sticks and large aggregated blocks, as shown in red and yellow colors in the composite images determined as $\mathrm{TiO}_{2}$ nanoparticles that have a uniform diameter $2 \sim 5 \mu \mathrm{m}$ and appear to be more uniformly dispersed in $5 \% \mathrm{~Pb}(\mathrm{SCN})_{2}$ doped$\mathrm{FA}_{0.9} \mathrm{Cs}_{0.1} \mathrm{PbI}_{3} .5 \% \mathrm{~Pb}(\mathrm{SCN})_{2}$ doped-FA ${ }_{0 .} \mathrm{Cs}_{0.1} \mathrm{PbI}_{3}$ has hence an effective charge transfer between perovskite and $\mathrm{TiO}_{2}$. The STXM results indicate that the interaction between $\mathrm{mp}-\mathrm{TiO}_{2}$ and perovskite plays a key role in determining the PCE performance. The morphology variation of perovskite is correlated with $\mathrm{mp}-\mathrm{TiO}_{2}$ and $\mathrm{Pb}(\mathrm{SCN})_{2}$, which illustrates that the interaction between mp- $\mathrm{TiO}_{2}$ and perovskite is not favored to grow large and defect-free perovskite layers for charge transfer.
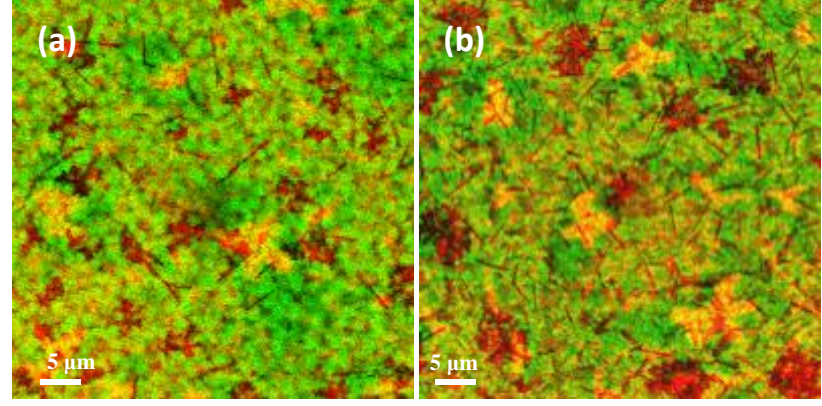

Figure 2. Chemical mapping of Ti $L$-edge (red) and $\mathrm{N} K$-edge (green) of (a) $\mathrm{SiN} / \mathrm{mp}-\mathrm{TiO}_{2} / 5 \%$ $\mathrm{Pb}(\mathrm{SCN})_{2}$ doped-FA ${ }_{0 .} \mathrm{Cs}_{0.1} \mathrm{PbI}_{3}$, and (b) $\mathrm{SiN} / \mathrm{mp}-$ $\mathrm{TiO}_{2} / 10 \% \mathrm{~Pb}(\mathrm{SCN})_{2}$ doped-

$\mathrm{FA}_{0.9} \mathrm{Cs}_{0.1} \mathrm{PbI}_{3} \mathrm{FA}_{0.9} \mathrm{Cs}_{0.1} \mathrm{PbI}_{3}$.

\section{References}

[1] M. A. Green, et al., Nat. Photonics, 8, 506 (2014).

[2] M.-W. Lin, et al., Adv. Mater. Interfaces, 3, 1600135 (2016).

[3] Z. Xiao, et al., Adv. Mater., 26, 6503 (2014).

[4] The authors acknowledge funding from the Ministry of Science and Technology, National Synchrotron Radiation Research Center and the UVSOR-RIKEN collaboration program. 